\title{
Body piercing in the accident and emergency department
}

\author{
Rakesh Khanna, S Sathish Kumar, B Srinivasa Raju, A V Kumar
}

\begin{abstract}
Recently an increasing number of patients with complications related to pierced body jewellery have been seen. Often removal of the jewellery is indicated. Removal of these items may also be required for radiological purposes. If the doctor is familiar with the opening mechanism of the item, removal is not usually difficult. Uninformed attempts at removal may cause unnecessary trauma and distress. In a survey of 28 accident and emergency doctors, only six were able accurately to describe the opening mechanisms of all three commonly used types of jewellery. Descriptions of the types of jewellery currently used are not available in the medical literature. The aim of this article is to familiarise doctors with the types of jewellery used, describe their opening mechanisms, and suggest techniques for their removal. The complications of body piercing and the indications for the removal of body jewellery are also outlined.
\end{abstract}

(F Accid Emerg Med 1999;16:418-421)

Keywords: body piercing; jewellery

Over the last few years body piercing has become an increasingly popular expression of body art. Increasingly the vogue is for piercing and placing body jewellery in unconventional parts of the body such as the tongue, lips, labia, and even through the erectile tissue of the penis, nipple, and clitoris. These patients may present to the accident and emergency (A\&E) department with a variety of complications and it may be necessary for the jewellery to be removed in the department. Because the jewellery is radio-opaque removal may be required for standard radiography. This is especially important when cervical spine views are required in a patient with a "lingual bar" which may obscure the odontoid peg. They may also require removal to prevent scattering of computed tomographic scans and disturbance of the magnetic field when performing magnetic resonance imaging.

There are several reports of the complications of body piercing in medical literature including local and systemic infections, ${ }^{12}$ the possible transmission of hepatitis B and HIV, ${ }^{34}$ Ludwig's angina, ${ }^{5}$ and toxic shock syndrome. ${ }^{6}$ Dental journals have documented the complications of intraoral piercing. ${ }^{78}$ There have also been reports on significant local granulomatous reactions. ${ }^{9-11}$ The commonest complications are almost certainly bleeding, local infec- tion, and oedema of surrounding tissues leading to embedding of the jewellery.

We have seen a number of patients in our department with a variety of minor complications relating to body jewellery requiring its removal (box 1). Some difficulty was experienced in effecting this, prompting us to research this area. In the medical literature, there did not appear to be any detailed descriptions of the various types of studs and rings used by practitioners of this art nor of their opening mechanisms. The aim of this article is to outline the various types of body jewellery in use today, describe their opening mechanisms, review the potential complications of this "art form", and to suggest appropriate techniques to remove them in some of the different situations that may be encountered in an $A \& E$ department.

Out of 28 A\&E doctors surveyed, only six were able accurately to describe the opening mechanism of the three common types of jewellery shown in fig 1. Four doctors suggested unnecessary procedures such as incising of the surrounding tissue. This article addresses this deficit in information.

We interviewed four licensed body piercing practitioners who we questioned with regard to their licensing requirements and techniques used. We also procured a range of stainless steel body jewellery to dismantle, study, and photograph. The medical literature was reviewed in Medline using the OVID interface from 1986 to January 1999 for all entries relating to body piercing.

\section{Techniques used by "professional piercers"}

Licensed ear piercers usually carry out body piercing in the UK. The environmental department of the local council, which accesses the training of the applicant, vets them. The Body Piercing Association conducts training courses. After inspecting the proposed premises and ensuring that arrangements are

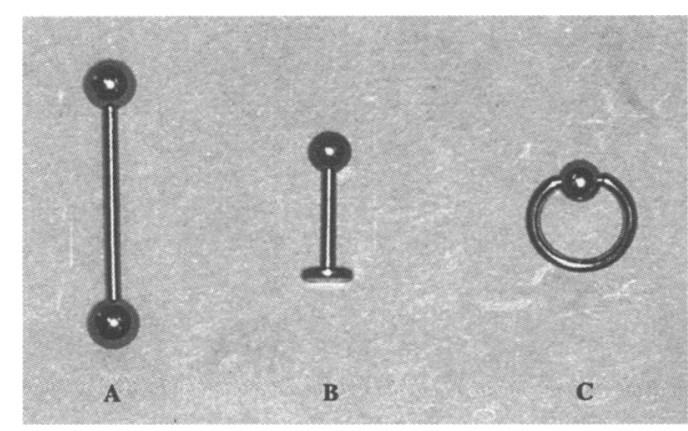

Figure 1 Example of types of body jewellery. (A) Barbell stud; (B) labret stud; (C) captive bead. 
in place for safe disposal of sharp instruments the council may issue a licence for ear piercing. The studios appear to perform a wide variety of procedures under this licence.

Currently in the UK body piercers are not allowed to use injectable local anaesthetics. The piercers we talked to were aware of the availability of effective topical local anaesthetics such as Emla. They do not stock it but can advise a patient to request their general practitioner for a prescription. Almost all of their work is done without any form of anaesthesia or occasionally with ethyl chloride spray. As a significant number of piercings currently performed are intraoral, this technique has very limited application. There appears to be awareness of the obvious complications such as bleeding, local swelling, and infection. Usually a larger size of jewellery is initially used to allow for the anticipated swelling and to prevent embedding. After a period of four to six weeks this is changed to a smaller size.

The standard technique employed is to pierce the body with a large bore intravenous type cannula, remove the needle, pass the opened jewellery into the lumen of the cannula, and withdraw the cannula back through the tissues. A variety of propriety "guns" are also available but their use is limited mostly to ear piercing.

\section{Types of jewellery used}

There are three basic types of jewellery in current use, although there are many variations of these designs.

\section{(1) BARBELL STUDS (FIG 1A)}

These are straight bars with a ball threaded onto both ends. The commonest site of usage is through the tongue. Smaller studs of this type are also passed through the glans penis and clitoris. These bars may be curved (banana type) or even form an incomplete circle for use around the navel, eyebrow, and nipple.

\section{(2) LABRET STUDS (FIG 1B)}

These are straight bars with a ball threaded on one end and a disc permanently fixed onto the other. They are used mostly for lower lip and oral piercings with the ball usually being exposed to the exterior and the flat disc

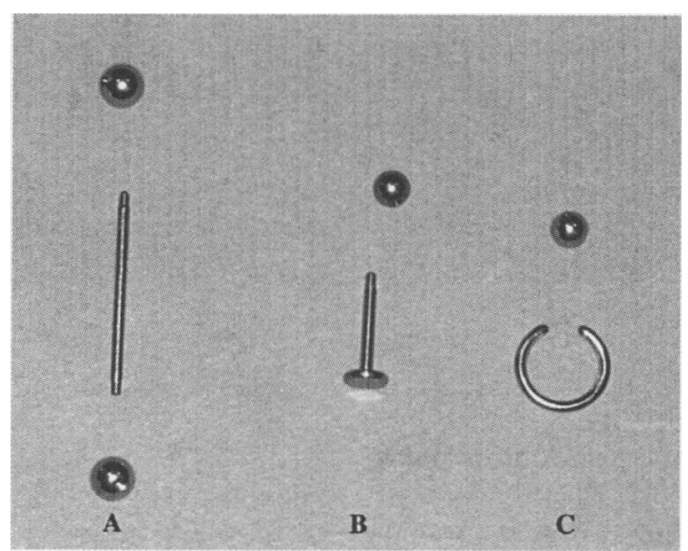

Figure 2 Examples shown in fig 1 with beads detached. In $(A)$ and $(B)$ they have been unscrewed; $(C)$ required distraction of the ring.

\section{Box 1 \\ Case reports}

Patient 1: A teenage girl attempted suicide by partial hanging. She was in cervical immobilisation. Clinically she had decorticate rigidity suggestive of anoxic brain damage. The radiographer requested removal of a lingual bar to visualise the odontoid peg and to facilitate computed tomography. It was removed by the technique illustrated in fig 5 .

Patient 2: A young man presented with a self diagnosis of "hernias in both groins". Examination revealed bilateral inguinal lymph nodes associated with an infected navel ring. Removal of the ring with a short course of antibiotics resulted in a rapid resolution of symptoms.

Patient 3: A teenage boy attempted to pierce his eyebrow with a copper wire, which he intended to use to draw some body jewellery through the tissues. The wire fractured and a piece of it was retained in the soft tissues of his forehead.

retained intraorally. These may be removed by unscrewing the ball (fig 2B).

(3) CAPTIVE BEAD RING (FIG 1C)

These consist of a bead with small dimples on opposite sides which is held "captive" by tension from both sides of an incomplete ring. Removal is achieved by distracting the ring using two clips. The manufacturers claim that they are easy to insert and remove, although we did not find it so. A variation of this is the "bead ring", in which one bead is coupled permanently to one end, opening being effected by removing the free end of the ring.

\section{Indications for removal}

The commonest complications are local oedema (leading to embedding of the jewellery), infection (local, regional, and systemic), and bleeding. The frequency of these complications does not appear to have been determined, although we understand from our discussions with body piercers that this maybe up to $30 \%$. Removal may also be required for radiological purposes in the conscious or unconscious patient. Local trauma to the pierced site may require removal for immediate management of tissue damage. While removing any form of intraoral jewellery the risk of accidental aspiration must be considered.

\section{Suggested techniques for removal}

Usually patients will be able to remove the jewellery themselves, but this may not be possible in the presence of significant tissue oedema, infection, or in difficult positions such as in the mouth.

Removal of the barbell, its variants, and labret type studs may be effected by holding the bar with an artery forceps and unscrewing the bead with another (fig $2 \mathrm{~A}$ and $\mathrm{B}$ ). Where this type of jewellery is embedded (fig 3 ) it is best to compress the oedematous tissue, push 


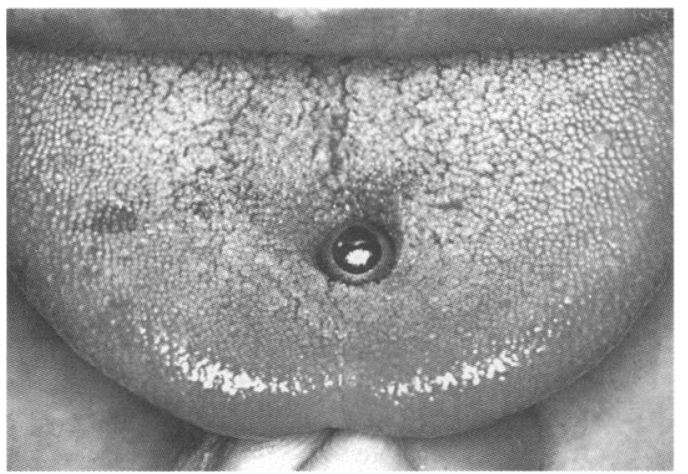

Figure $3 A$ barbell stud embedded in oedematous tissue.

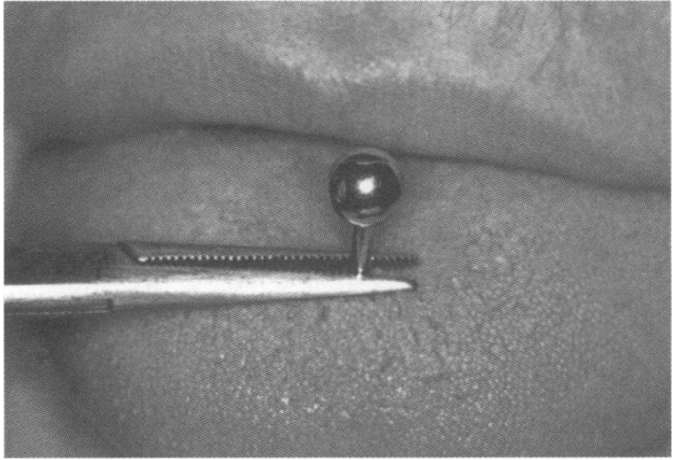

Figure 4 The same patient; stud has been exposed by compressing the oedematous tissues and pushing the stud from below making removal easier.

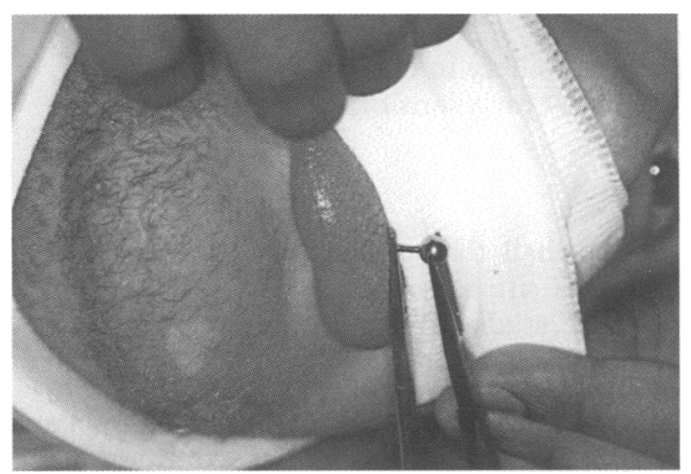

Figure 5 Suggested technique for removing lingual bar in an unconscious patient with or without cervical immobilisation.

the jewellery through it to expose the bead so that it can be grasped, and removed with forceps (fig 4). It should very rarely be necessary to incise any tissue.

The captive bead ring and its variants may be removed by holding the ring on either side of the captive bead and releasing the tension on the bead (fig 2C). In the unconscious patient we suggest that lingual barbells be removed by exteriorising the jewellery if possible and placing a swab behind the bead as it is unscrewed to prevent possible aspiration (fig 5).

\section{Discussion}

Over the last few years body piercing has become very popular within a large proportion of the population. Figures regarding its prevalence have not been documented, but some idea of its popularity can be gleaned from the fact that within just the North Birmingham and Staffordshire areas alone there are over 20 studios offering body piercing services. All the studios we contacted reported excellent business, some with lengthy waiting lists. The reasons behind its popularity are complex and beyond the scope of this article but have been dealt with elsewhere. ${ }^{11}$ As several popular personalities have taken to wearing body jewellery (especially lingual bars), its popularity can be expected to increase. There have been a few reports in the medical literature about the obvious complications of such procedures such as oedema and local infection. ${ }^{12}$ From our discussions with body piercers and wearers we believe these to be very common problems. None of the body piercers we spoke to were aware that invasive intraoral procedures should only be carried out under antibiotic cover in patients with cardiac murmurs. Surprisingly there has not been a single case report in the literature regarding this or other obvious potential complications such as excessive local bleeding or nerve damage.

The medical profession must, we believe, be concerned about the vogue in "extreme" piercing, which includes in males piercing of the distal urethra (the so called "Prince Albert"), scrotum, frenulum, and through the glans penis itself. In females both the labia minora and majora, the clitoral hood, and clitoris itself may be pierced. There are many variations of these basic themes involving the use of chains and locks in addition to the body jewellery. Descriptions of these are beyond the scope of this article but the curious can easily find details of all these by searching the world wide web using the words "body piercing" on any search engine. Under UK law female genital mutilation is specifically prohibited. Although this legislation was designed to prevent female circumcision, such extreme piercings may well be considered to be a form of mutilation. The British government appears to have taken notice of these issues and at the time of writing had announced that it proposes to introduce legislation to regulate body piercing. The scope of the proposed legislation has not yet been announced.

A doctor may be requested to remove body jewellery by a wearer for a variety of medical and social reasons. In some circumstances, as described, it may be medically necessary to remove the jewellery in the conscious or unconscious patient. If the doctor is not familiar with the design of the item this may prove difficult to do. We hope that this article will prove useful to medical professionals in this area.

We would like to $\mathrm{Mr}$ Kevin Jukes, professional body piercer Stafford, for his help in the preparation of this article. We would also like to thank Mr Alistair Rose, medical photographer, Staf fordshire District Hospital for preparing the photographs.

Funding: none.

Conflict of interest: none.

\section{Contributors}

Rakesh Khanna initiated and participated in the design of the study, discussed core ideas, conducted the survey, interviewed professional body piercers, participated in data collection and writing of the paper. S Sathish Kumar discussed core ideas, participated in data collection, coordinated the artwork, and participated in the writing of the paper. B Srinivasa Raju discussed core ideas, interviewed professional body piercers, participated in data collection and writing of the paper. A V 
Kumar discussed core ideas, participated in the design of the study, contributed to and participated in the writing of the paper.

Rakesh Khanna is the guarantor for the article.

1 Cumberworth VL, Hogarth TB. Hazards of ear piercing procedures which traverse cartilage: a report of pseudomonas perichondritis and review of other complications. Br F Clin Pract 1990;44:512-13.

2 Tweeten SS, Rickman LS. Infectious complications of body piercing. Clin Infect Dis 1998;26:735-40.

3 Hvolris J. [Hepatitis transmitted by ear piercing] [Danish]. Ugeskr Laeger 1991;153:119.

4 Pugatch D, Milerno M, Rich JD. Possible transmission of human immunodeficiency virus type 1 from body piercing. Clin Infect Dis 1998;26:767-78.

5 Perkins CS, Meisner J, Harrison JM. A complication of tongue piercing. Br Dent $\mathcal{\Im}$ 1997;22:147-8.
6 McCarthy VP, Peoples WM. Toxic shock syndrome after ear piercing. Pediatr Infect Dis $\mathscr{f}$ 1998;7:741-2.

7 Cobb DS, Denehy GE, Vargas MA. Adhesive composite inlays for the restoration of cracked posterior teeth associated with a tongue bar. Practical Periodontics and Aesthetic Dentistry 1998;10:453-60.

8 Boardman R, Smith RA. Dental implications of oral piercing. Fournal of the Californian Dental Association 1997; 25:200-7.

9 Zilinsky I, Tsur H, Trau H, et al. Pseudolymphoma of the ear lobes due to ear piercing. fournal of Dermatology and Surgical Oncology 1989;15:666-8.

$10 \mathrm{Ng} \mathrm{KH}$, Siar CH, Ganesapillai T. Sarcoid like foreign body reaction in body piercing: a report of 2 cases. Oral Surg Oral Med Oral Path Oral Radiol Endod 1997;84:28-31.

11 Wright J. Modifying the body: piercing and tattoos. Nursing Standard 1995;10:27-30.

12 Turkeltaub SH, Habal MB. Acute pseudomonas chondritis as a sequel to ear piercing. Ann Plast Surg 1990;24:279-82. 